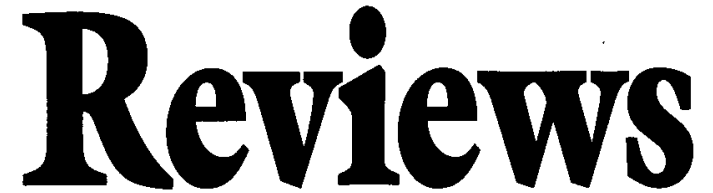

\title{
Minimizing Environmental Stress in Field Establishment of Vegetable Crops in the Southwestern United States
}

\section{T.K. Hartz}

Additional index words. temperature, salinity, soil structure, damping-off

Summary. Overcoming environmental stresses during seedling establishment is crucial to successful vegetable production. In the irrigated production areas of the southwestern United States, stress most often is related to unfavorable temperature, soil or water salinity, or poor soil structure; it is frequently difficult to separate the effects of these stresses because they may all be present to some significant degree. Growers use a variety of techniques to ameliorate these conditions. Advances in seed technology have improved seedling establishment under unfavorable temperatures, particularly for lettuce. The use of sprinkler irrigation for stand establishment has become a widespread practice; sprinkling moderates soil temperature, minimizes salinity in the zone of germination, and reduces soil crusting. By modifying bed configuration, growers have been able to increase soil temperature to stimulate germination. Modifying seed placement and furrow irrigation patterns can create zones of lower salinity. Various chemical and physical treatments have proven effective in re-

Vegetable Crops Department, University of California, Davis, CA 95616.

The tort of publishing this paper was defrayed in part by the payment of page charges. Under postal regulations, this paper therefore must be hereby marked advertise ment solely to indicate this fact. ducing soil crusting. The use of transplants-has expanded for many crops, both as a means to circumvent seedling establishment problems, as well as a technique to obtain earliness.

A thieving a plant stand of uniform spacing and maturity is the foundation of successful commercial vegetable production. This is particularly true in the irrigated areas of the southwestern United States, where sophisticated production systems put a premium on uniformity and efficiency. Field conditions are seldom ideal, and economic incentives often induce growers to plant when conditions are clearly suboptimal. A number of specialized practices have been developed to combat environmental stresses during stand establishment. This review outlines these practices as they relate to the most serious stress problems encountered: temperature, soil salinity, soil crusting, and loss to soil-borne pathogens.

\section{Temperature}

Ideal soil temperatures for germination of the common vegetable crops are known, but economic incentives frequently push growers to plant under less than ideal conditions. Market premium for earliness, a need to double-crop to recoup land costs, and the need to use a packing or processing facility over the longest possible season often drive growers to plant coolseason crops such as lettuce, carrot, crucifers, and onions under hot conditions in "late summer or early fall, and warm-season crops (cucurbits, tomatoes, peppers) during the cool weather of late winter/early spring.

The best illustration of high-temperature stress management is California's Imperial Valley, a desert production area bordering Mexico. It is a primary source of winter lettuce, carrots, and crucifers for the United States. Seeding of these cool-season crops begins as early as August, when mean daily maximum air temperature exceeds $100 \mathrm{~F}$. Soil temperatures are correspondingly high; in the seed zone dry soil can exceed $120 \mathrm{~F}$.

Thermal dormancy in lettuce can be induced by such extreme conditions. Two practices are used at present to deal with this problem. Seed priming treatments have been developed that can alleviate thermal dormancy effectively (Guedes and Cantliffe, 1980; Valdes et al., 1985); the majority of early fill-planted lettuce in the Imperial Valley is now primed.

Thermal dormancy also can be minimized by irrigation management. In a dry condition, lettuce seed can tolerate short-term exposure to very high temperatures; however, once seed is imbibed, exposure above 90F can result in prolonged dormancy. Growers seed into dry soil, then begin irrigation in the afternoon; by the time the seeds are imbibed, the cooling effect of the irrigation water and the lowered temperatures of evening drop seed zone temperature below 90F, where it remains until mid-morning of the following day. Physiological activity of the lettuce seeds is very rapid; within $\approx 12 \mathrm{~h}$ from imbibition, the germination sequence has proceeded beyond the step affected by thermal dormancy.

Although the other cool-season crops do not have a defined thermal dormancy, their establishment under extreme heat is still problematic. Some seed lots lack the vigor to emerge uniformly in extreme temperatures, although these lots may perform well later in the fall under more favorable conditions. This has prompted many seed dealers to conduct high-temperature germination tests to identify suspect seed lots, which they then withhold until cooler weather. There has 


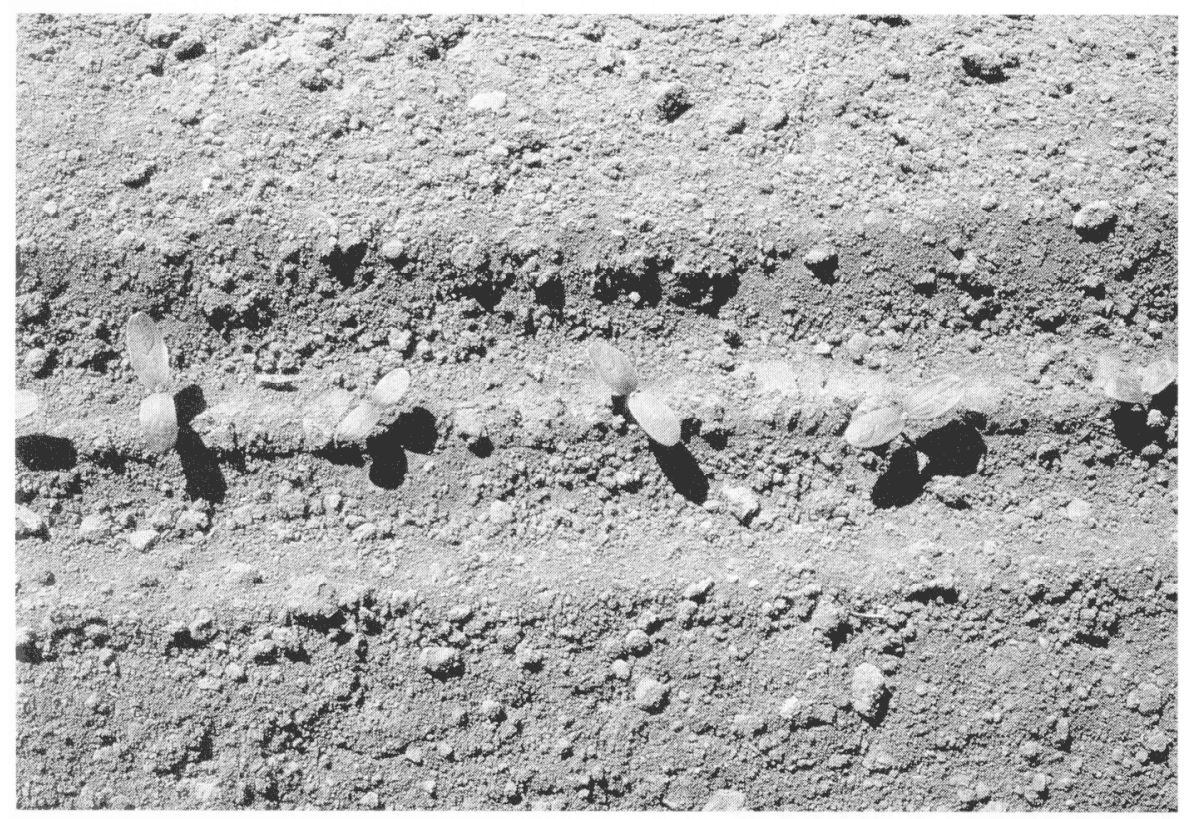

\section{A uniform plant stand is critical for efficient vegetable production.}

been considerable research on seedpriming treatments to improve carrot germination, but commercial use of primed seed is relatively uncommon.

Even vigorous seed lots or primed seeds capable of high-temperature germination encounter difficulties in field establishment. These crops are very shallowly seeded and, under furrow irrigation, the seed zone encounters wetting and drying cycles. The high degree of evaporation from the soil surface also causes salts to concentrate near germinating seedlings. Many loworganic-matter mineral soils also form dense crusts that physically restrict plant emergence.

All of these problems can be addressed by using sprinkler irrigation to establish stands. With proper use of sprinklers, seed-zone moisture fluctuations are minimized, soluble salts are flushed below germinating seedlings, and soil crust formation is minimized. Sprinkling to establish stands in early fall-planted fields of cool-season crops became commonplace in the Imperial Valley in the 1970s and now is used by nearly all growers there. Once the crop has emerged and is actively growing, the sprinklers are removed and furrow irrigation is used to complete the season. Despite substantial cost (custom rates can exceed $\$ 120 /$ acre), sprinkler irrigation for stand establishment is increasing in popularity throughout the western United States wherever crops such as lettuce, carrot, and crucifers are grown.

A more widespread problem than establishment of cool-season crops in hot weather is starting warm-season crops in cool soil. Almost everywhere cucurbits, tomatoes, and peppers are grown, market forces press growers to plant early. Many techniques have been tried over the years to cope with this problem. Massive overseeding to ensure adequate stand was the simplest approach. Muskmelon growers in the Imperial Valley or the lower Rio Grande Valley of Texas commonly seeded as much as 3 to $4 \mathrm{lb}$ /acre on early plantings, roughly seven to eight seeds for every plant desired; this approach was used on other crops as well. The advent of hybrid varieties, with seed costs
Sprinkler irrigation can improve stand establishment. many times higher than standard openpollinated lines, has made overseeding an uneconomical option.

Research in seed-priming techniques to improve speed and uniformity of germination in cold soils (Nelson and Sharples, 1980; Rivas et al., 1984; Sachs, 1977; Sundstrom et al., 1987; Yaklich and Orzolek, 1977) has shown a measure of success in laboratory trials, but field performance trials of primed melon, tomato, and pepper seed have yielded mixed results. These equivocal results, together with the substantially increased cost of primed seed, have, to date, minimized grower acceptance of seed-priming for the warm-season crops, except for the production of greenhouse-grown transplants, where high germination percentage and uniformity of emergence are critical.

Gel-seeding is another idea whose time has never come. The concept is sound: Uniformly germinate seeds under controlled conditions, then suspend the seeds in a gel and plant plugs of the mixture in the field (Gate and Phatak, 1982; Gray, 1981; Pill, 1991). The temperature-sensitive steps of the germination process are accomplished before going to the field. Considerable effort went into the development of germinating and planting equipment, and workable systems were built, but the idea never caught on with the major produce companies in the southwestern United States because it increased the complexity of seeding operations dramatically. There are also

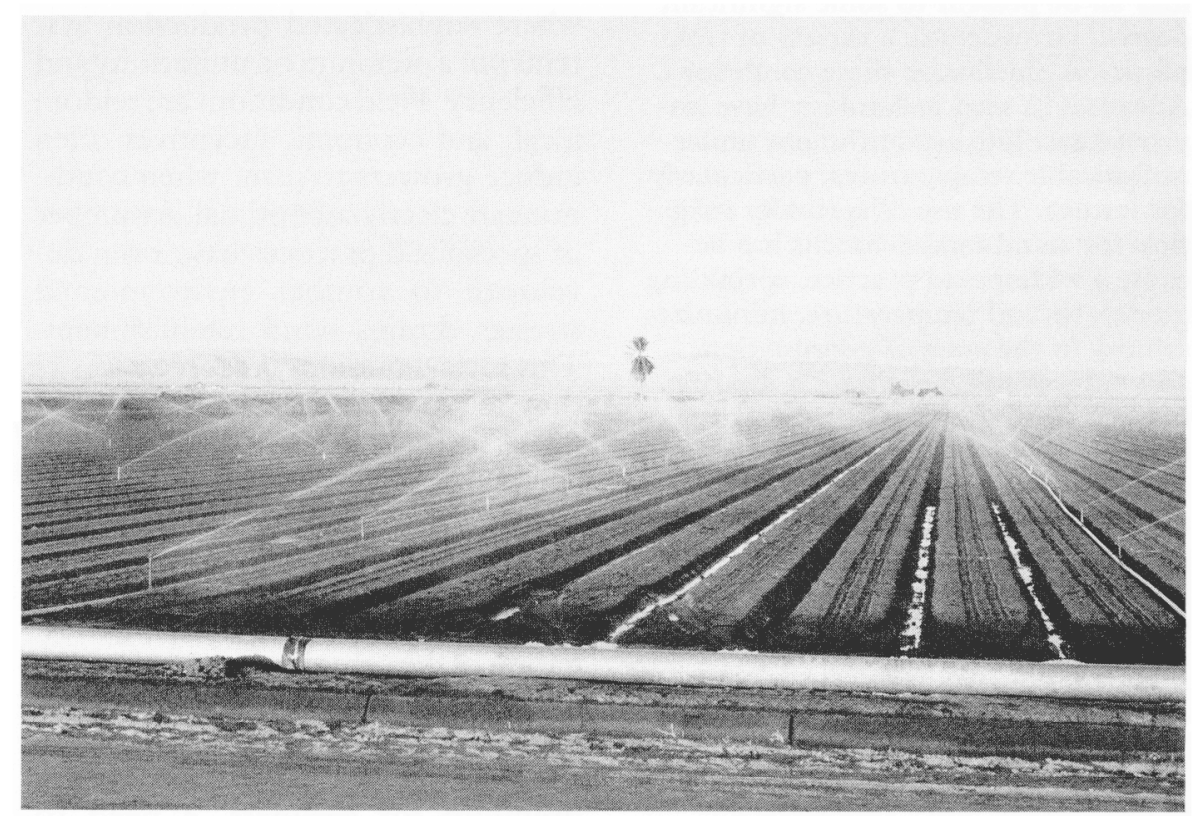


the issues of the capacity of the gelseeding units (which are slower than conventional seeders) and added costs. No major southwestern U.S. vegetable grower uses gel-seeding on a routine basis.

Overseeding, seed-priming, and gel-seeding were simply responses to adverse environmental conditions rather than attempts to ameliorate them. Other techniques actually modified the seedling environment. Changing the configuration of the bed can modify soil temperature substantially. In the Imperial and Yuma valleys, muskmelon growers found that, by orienting rows east-west and sloping soil beds $\approx 30^{\circ}$ to $35^{\circ}$ to the south, seedzone temperatures could be increased $4-6 \mathrm{~F}$. When seeded on the southfacing slope, muskmelon germination was enhanced significantly. Today, much of the early spring muskmelon crop is planted on these slant beds. The increased tillage costs associated with slant-bed culture (up to $\$ 80 /$ acre) are more than offset by earlier production. The use of bed configuration as a tool to modify soil temperature has not caught on in other production areas, despite its potential utility on tomatoes or other cucurbits.

A related practice is the use of black petroleum mulch banded over the seed rows of Imperial Valley muskmelon fields. The band, $\approx 4$ inches wide, further increases seed-zone temperature. It also minimizes soil crusting. This technique has been tried with some success elsewhere, but, at present, large-scale usage is limited to the Imperial and Yuma valleys.

The use of polyethylene mulch films for soil temperature modification has much wider use. Clear polyethylene films have been used widely for years to increase soil temperature. Its use has been limited to fumigated fields due to weed control problems. New film products with modified infrared transmission characteristics have become available in recent years; this technology allows the use of pigmented (black, brown, green) films, which provide weed control while still providing substantial soil warming. It is difficult to assess directly the impact of polyethylene mulch on stand establishment because mulched fields usually are established with transplants or a specialized seeding technique. It is safe to say that, to the extent mulch warms soil and speeds early season growth, it is

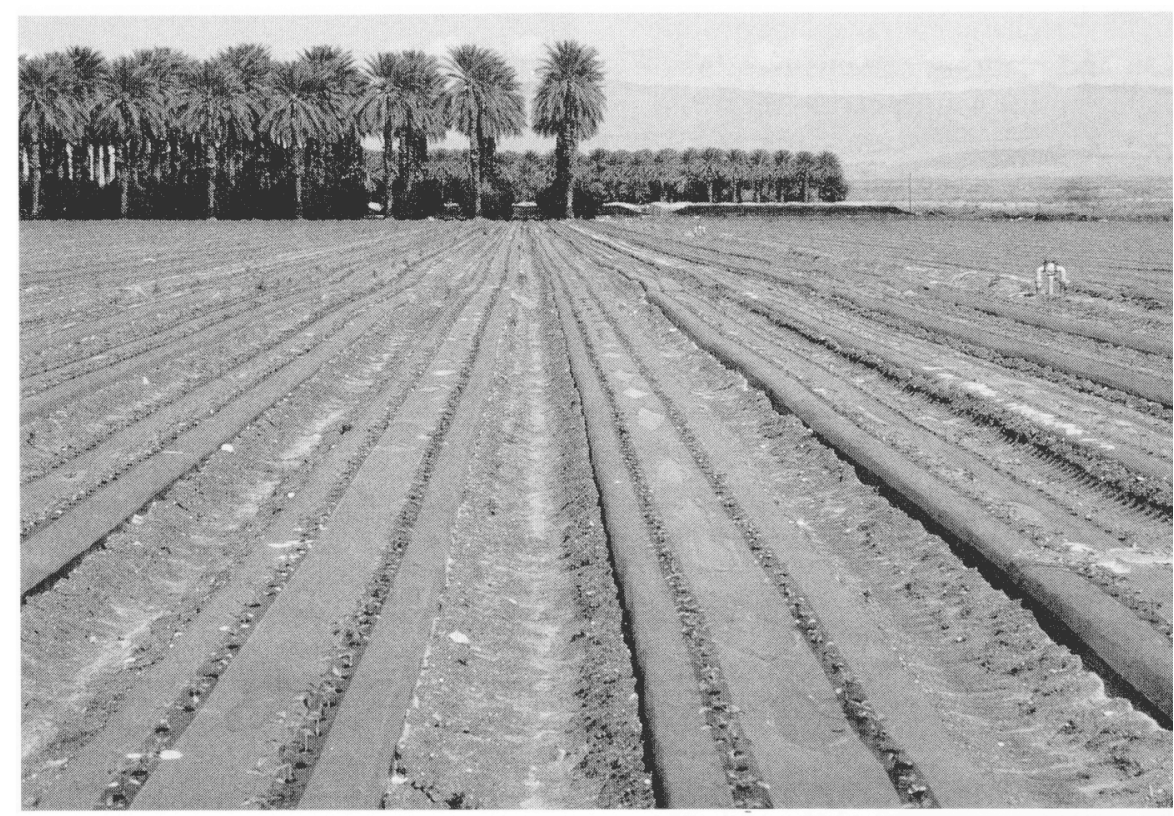

Transplanting into polyethylene mulch is common for early spring planting of warm season crops.

minimizing environmental stress on stand establishment. Limitations, mainly high costs and difficulties in mating mulch use with furrow or sprinkler irrigation, restrict its use primarily to drip-irrigated fields of tomatoes, peppers, and early spring cucurbits. less than 30,000 acres of vegetable crops in the western United States are grown using polyethylene bed mulch.

Plug-seeding, a technique developed for use with plastic mulch, deserves mention. Dry seed is bulk-mixed with a dry peat-vermiculite medium. This mixture then is wetted to imbibe the seeds and planted in 2- to 3-inch ${ }^{3}$ plugs through the plastic mulch; the planting is done either by hand or mechanically. This approach gives more-rapid, uniform emergence than planting dry seed. Plug-seeding has been used on a commercial scale on spring melons in Texas, but is not a common practice elsewhere.

The most cost-intensive practice to combat low temperatures is the use of hot caps or rowcovers. In the past, covering individual plants with paper or plastic hot caps was a widespread practice; in California, thousands of acres of spring cucurbits, tomatoes, and peppers were started with hot caps. However, this practice was extremely labor-intensive and, as wages increased, hot cap usage decreased. Few commercial growers still use individual plant covers today.

A related approach is the use of polyethylene or spun-bond fiber rowcovers. Rowcovers can provide sub- stantial freeze protection and, depending on material, can increase air and soil temperatures significantly. Rowcovers are mechanized more easily than hot caps, and they can be used for a larger portion of the crop season. Costs of using rowcovers, whether with wire hoops or in a lay-flat configuration, are still very high; their use is limited to less than 15,000 acres in California and still fewer acres in Arizona and Texas.

Perhaps the most significant technique for dealing with suboptimal temperature effects on stand establishment is transplanting. Transplanting circumvents problems with the temperaturesensitive physiological processes of germination, as well as minimizing losses to damping-off pathogens. If properly executed, transplanting can assure near-perfect stands, even under extreme field conditions.

Historically, most vegetable crops in the southwestern United States were direct-seeded. Celery was an exception; the extraordinary difficulty in obtaining full, uniform field stands made costly, labor-intensive transplant production a viable alternative. In the past 20 years, several important changes in the vegetable industry have broadened the use of transplants significantly. The advent of costly hybrid seed has eliminated overseeding as an option. Market demands have expanded planting seasons in many production areas, exacerbating stand-establishment problems. Most important, the development of sophisticated, 
highly mechanized transplant production and planting systems have made transplanting a more economical practice, particularly for crops that require high plant populations. Today, significant acreage of the following crops are transplanted in the western United States: Asparagus, cauliflower, celery, lettuce, pepper, tomato, and watermelon. As seed costs continue to escalate and transplant systems become even more efficient. the use of transplants will continue to increase.

\section{Salinity}

Throughout the irrigated southwestern United States, soil and water salinity problems exert a significant negative impact on stand establishment of vegetable crops. This impact can be direct-through depression of the osmotic potential of the soil solution-or indirect-through detrimental effects on soil structure. It is important to identify the nature of the problem before an appropriate remedy can be considered.

Periodic monitoring of soil salinity levels can identify problem fields. In severe cases. such as areas of high water table, inadequate internal drainage, or sodic conditions, intensive reclamation procedures (drain tiling, use of soil amendments. etc. ) are required before vegetable cropping can be contemplated (Oster et al., 1984). Once these remedies have been initiated. extensive leaching is needed to reduce salt content to manageable levels.

In less-severe cases, where a slow buildup of soil salts has resulted from routine cropping practices, periodic leaching is usually sufficient. In the desert regions of California and Arizona, growers commonly flood fields annually during the summer fallow period to provide adequate leaching to minimize salt buildup. Heavy pre-irrigation of listed fields, practiced throughout the western United States, has similar effect. Ideally, preplant soil electrical conductivity (a measure of soluble salt content) should be $3 \mathrm{dS} \cdot \mathrm{m}^{-1}$ or less; even at this level, extremely salt-sensitive crops, such as carrot, can be affected.

Salt content of the irrigation water is the other important salinity factor in stand-establishment problems. Surface water supplies in the southwestern United States vary from $<150$ parts per million $\left(0.25 \mathrm{dS} \cdot \mathrm{m}^{-1}\right)$ to $>2000 \mathrm{ppm}\left(>3 \mathrm{dS} \cdot \mathrm{m}^{-1}\right)$. Well waters

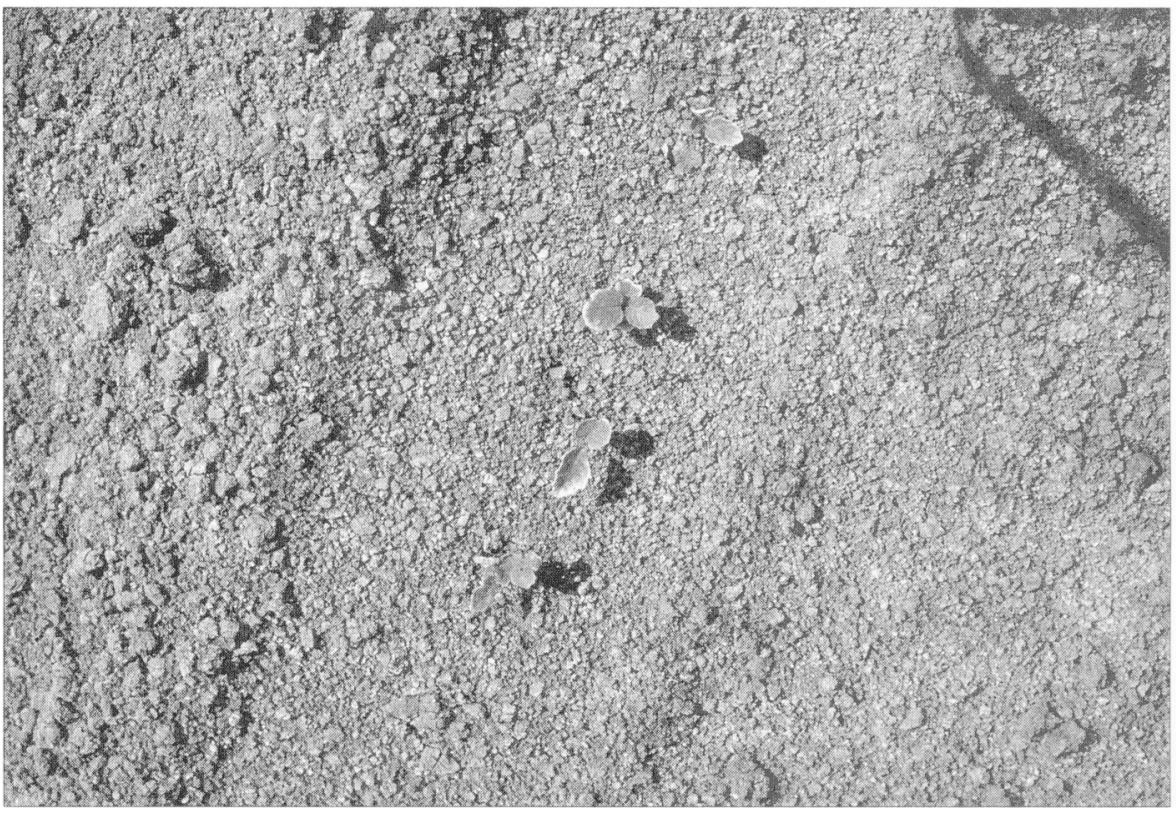

High seedbed salinity can reduce stand establishment and plant vigor.

are seldom $<500$ ppm and can exceed $3000 \mathrm{ppm}$. Even where pre-plant soil salinity levels are suitable, salts added in the irrigation (when concentrated in the seed zone by evaporation of water from the soil surface) can impede germination. During hot weather, when evaporation can exceed 0.4 inch/ day, salts in the top inch of soil can reach deleterious levels.

Growers have a number of options for dealing with salinity effects. The most obvious is crop selection. Problem fields are planted to salt-tolerant crops such as cotton, sugarbeets, or grains. Among vegetable crops, broccoli and tomato are considerably more salt-tolerant than lettuce or carrot.

It is widely known that seedling establishment is the most salt-sensitive growth stage for most crops. Many farms have several water sources of varying qualities available to them, either multiple wells pulling from different aquifers or a combination of wells and surface waters. Where possible, growers will use the highest-quality water available during stand establishment; then, if necessary, switch to or blend-in poorer-quality water to complete the crop. Once established, crops such as tomato can tolerate quite high salinity levels (Mitchell et al., 1991).

Manipulating bed shapes or planting configurations can ameliorate salinity effects (Oster et al., 1984). Soluble salts in soil move with the wetting front, resulting in areas of higher and lower salinity. With furrow irrigation, the lowest salt content is near the furrow and the highest at the edge of the wetting pattern or where the wetting fronts of adjacent furrows meet. On the standard double-plantrow bed used for many vegetable crops, it is common to plant near the bed edges and build a soil ridge, or "salt crown," in the bed center. This configuration serves to move salts away from the seed zone. In crops where a single row per bed is the norm (i.e., cauliflower), offsetting the plant row and irrigation in alternate furrows serves the same purpose.

By far the most valuable tool for minimizing salinity effects on stand establishment is sprinkler irrigation. The initial irrigation moves most soluble salts below the seed zone, and daily applications until seedling emergence minimize soil crusting and continually flush salts, concentrating from evaporation, from the soil surface. Stand improvements with sprinklers can be dramatic, and the uniformity of emergence is improved. It is not unusual for fall-seeded lettuce and carrots to emerge over a 7- to 10-day period where furrow irrigation is used, whereas in equivalent sprinkler-irrigated fields, the vast majority of plants emerge over a shorter period. The potential improvement in harvest efficiency is obvious.

\section{soil crusting}

Soil crusting is a serious impediment to stand establishment through- 
out the western United States. The root causes can be chemical or physical. Most of the western U.S. irrigated soils are very low in organic matter, and soil aggregates tend to be somewhat unstable. Water, whether from irrigation or rainfall, can break down aggregates and cause serious crusting problems.

The degree of crusting depends on a number of factors. Soluble salt content and sodium absorption ratio (SAR) of the water is important; water $<200$ ppm or with a high SAR will tend to promote crusting (Oster et al., 1984). SAR of soil is important as well; sodium acts as a deflocculating agent, while calcium and magnesium promote aggregate stability. Soil texture and the type of clay minerals present influence crusting, but nearly all loworganic-matter soils will crust under the right conditions. One of the biggest factors in crusting is precipitation during stand establishment. The physical impact of rain droplets can break down surface soil aggregates; as little as $0.5 \mathrm{~cm}$ of rain can cause severe crusting.

Growers use a variety of approaches to combat crusting. Various tillage tools have been developed that can break up crusted soil without destroying emerging seedlings. These socalled "crust busters" are in widespread use. Attempts have been made to use non-crusting soil amendments, such as vermiculite, over the seed line. Although the utility of that practice can be demonstrated experimentally, the cost and the difficulty in mechanizing the operation on a large scale has prevented this technique from achieving widespread acceptance. A similar approach is the use of organic polymers (i.e., Nalco 2190) sprayed over the seed row to stabilize soil structure (Hoyle, 1983; Page and Quick, 1979). Cost, again, has been an issue, but new computer-controlled application equipment can reduce the amount of material required; however, the treatment is not practiced widely.

Many western soils are calcareous (contain precipitated calcium carbonate). In such soils, the application of an acidifying agent (sulfutric or phosphoric acid, or acid-based fertilizers) on the soil surface will dissolve some calcium carbonate, putting additional calcium in soil solution, in theory displacing some sodium on soil exchange sites and reducing crusting potential
(Hemphill, 1982a, 1982b). This technique is relatively inexpensive (particularly if the applied material has fertilizer value) and is compatible with other cultural practices. This technique has been used relatively widely.

\section{Pest pressure}

No discussion of stand establishment difficulties should ignore the interaction of environmental factors, particularly soil temperature and aeration, on plant losses to soil-borne seedling diseases. Pythium and Rhizoctonia sp. are the primary damping-off pathogens, although other organisms can be involved on certain crops. Rhizoctonia and Pythium are essentially ubiquitous in agricultural soils; whether or not significant disease expression occurs depends on environmental conditions. Certain species are active within a confined temperature range, but the various damping-off organisms effectively span the range of soil temperatures from cool to very warm. Two generalizations can be made regarding damping-off severity: The longer the germination and establishment period of a seedling, the more likely soil-borne disease will be encountered; and poor soil aeration, whether caused by overirrigation, rain, poor soil structure, or soil crusting, will increase disease potential.

Broad-spectrum chemical fumigants, such as methyl bromide, chloropicrin, 1,3-dichloropropene, and metam sodium, can be highly effective in controlling damping-off organisms; the costs associated with these treatments limits their use to high-value crops. In general, the decision to fumi gate is made on the basis of other pest problems (i.e., weeds, nematodes), and control of damping-off is viewed as an additional benefit. Soil polarization has been highly effective against the common damping-off organisms (Katan and DeVay, 1991); again, cost has kept this practice from being accepted widely.

More commonly, growers seek to minimize seedling loss by careful soil preparation and irrigation, and by the use of fungicide seed and/or soil treatments. However, a significant problem looms on the horizon. Increasingly stringent governmental regulation of pesticides may result in the loss of a number of widely used fumgicides. Such restrictions will reduce grower options for controlling damping-off seedling losses.
In recent years, there has been extensive research on the use of biological seed treatments to suppress damping-off losses. Naturally occurring fungi or bacteria antagonistic to common damping-off organisms are applied to seed in a priming or coating treatment. Much of this research has been focused on supersweet (or sh2) corn, which tends to have very poor seed vigor (Callan et al., 1990, 1991; Parera and Cantliffe, 1990). Although a substantial degree of seedling disease suppression has been documented, biological seed treatments are seldom better, and frequently less effective, than conventional fungicidal seed treatments. To date, the commercial use of biological seed treatments to suppress damping-off losses is very limited.

In summary, establishing plant stands of uniform spacing and maturity is essential for commercial vegetable production. Growers encounter many forms of environmental stress; to effectively deal with these stresses, specialized practices have been developed involving seed technology, tillage, irrigation, planting systems, soil amendments, etc. By integrating these practices successfully, growers have been able to expand their cropping seasons and improve the efficiency of their operations.

\section{Literature Cited}

Callan, N.W., D.E. Mathre, and J.B. Miller. 1990. Biopriming seed treatment for biological control of Pythium ultimum preemergence damping-off in sh2 sweet corn. Plant Dis. 74:368-372.

Callan, N.W., D.E. Mathre, and J.B. Miller. 1991. Field performance of sweet corn seed bioprimed and coated with Pseudomonas fluorescens AB254. HortScience 26: 1163-1165.

Ghate, S.R. and S.C. Phatak. 1982. Performance of tomato and pepper seeds germinated before planting. J. Amer. Soc. Hort. Sci. 107:908-911.

Gray, D. 1981. Fluid drilling of vegetable seeds. Hort. Rev. 3:1-27.

Guedes, A.C. and D.J. Cantliffe. 1980. Germination of lettuce seeds at high temperature after seed priming. J. Amer. Soc. Hort. Sci. 105:777-781.

Hemphill, D.D. 1982. Phosphoric acid anticrustant improves seedling emergence and $\mathrm{P}$ content. J. Amer. Soc. Hort. Sci. 107:50-53. 
Hemphill, D.D. 1982. Anticrustant effects on soil mechanical resistance and seedling emergence. HortScience 17:39 1-393.

Hoyle, B.J. 1983. Crust control aids seedling emergence. Calif. Agr. 37(1):25-26.

Katan, J. and J.E. DeVay. 1991. Soil solarization. CRC Press, Boca Raton, Fla.

Mitchell, J. P., C. Sherman, S.R. Grattan, and D. May. 1991. Tomato fruit yields and quality under water deficit and salinity. J Amer. Soc. Hort. Sci. 116:215-221.

Nelson, J.M. and G. C. Sharples. 1980. Effect of growth regulators on germination of cucumber and other cucurbit seeds at sub optimal temperatures. HortScience 15:253-254.

Oster, J.D., G.L. Hoffman, and F.E. Robinson. 1984. Management alternatives: Crop, water and soil. Calif. Agr. 38( 10):2932.

Page, E.R. and M.J. Quick. 1979. A comparison of the effectiveness of organic polymers as soil anti-crusting agents. J. Sci. Food Agr. 30:112-118.

Parera, C.A. and D.J. Cantliffe. 1990. Improved stand establishment ofshrunken2 sweet corn by seed treatments. Proc. Fla. Host. Soc. 103:153-157.

Pill, W. G. 1991. Advances in fluid drilling. HortTechnology 1:59-65.

Rivas, M., F.J. Sundstrom, and R.L. Edwards. 1984. Germination and crop development of hot pepper after seed priming. HortScience 19:279-281.

Sachs, M. 1977. Priming of watermelon seeds for low-temperature germination. J. Amer. Soc. Hort. Sci. 102: 175-178.

Sundstrom, F.J., R.B. Reader, and R.L. Edwards. 1987. Effect of seed treatment and planting method on tabasco pepper. J. Amer. Soc. Host. Sci. 112:641-44.

Valdes, V.M., K. J. Bradford, and K.S. Mayberry. 1985. Alleviation of thermodormancy in coated lettuce seeds by seed priming. HortScience 20:1112-1114.

Yaklich, R. W. and M.D. Orzolek. 1977. Effect of polyethylene glycol-6000 on pepper seed. HortScience 12:263-264. 